\title{
TDS Content in bottled drinking waters
}

\author{
I.V.L.P.K.D. Deepika, L. Preethi, K. Gouru Naidu, K.V. Ramesh"
}

\begin{abstract}
A total of 25 water samples used for drinking purposes in Visakhapatnam were examined for their total dissolved solids (TDS) content using standard calibrated instrument. Among them 8 samples were obtained from sachets, four samples from one liter bottles and three samples are taken from 20 liter bottles. It was found that the TDS levels were at a minimum of $4 \mathrm{ppm}$ and at a maximum of 55, indicating that the TDS levels were very low and these waters are not suitable for potable purpose. Almost all famous brands available in the local market have been tested. Further, water from public RO units were found to be good with reference to TDS levels. Also, domestic water purifiers not employing RO unit also shown good waters as their product. It is felt that domestic water purifier with RO unit should be purchased only in case of waters with high TDS contents. It can be inferred that the commercial drinking waters are not at all meeting the statutory requirements and not good for human health if consumed for longer periods.
\end{abstract}

Index Terms - Drinking water, potable, RO, TDS, standards

\section{INTRODUCTION}

Now-a-days as the potable water resources are depleting efforts are being diverted to supply purified water to all the public. Those who can afford are buying bottled waters. In some localities the governments or NGOs are supplying potable waters by constructing RO water plants. However, it is understood that these waters do not meet the standards as laid out by BIS. The World Health Organization (WHO) [1] or Bureau of Indian Standards (BIS) specifies that the total dissolved solids should be up to a maximum of $500 \mathrm{ppm}$. Few earlier studies on bottled waters revealed that the companies are not following the norms laid down by the statutory agencies [2]. It is in this regard in the present investigation, studies are carried out to find out the TDS content in these waters.

\section{PROCEDURE}

Standard procedures have been adopted for estimation of total dissolved solids in the present investigation [3]. Measurement of TDS is carried out by using a standard and calibrated instrument.

\section{RESUILTS AND DISCUSSION}

Table. 1 shows the TDS content in various brands of mineral water sachets of $200 \mathrm{ml}$ volume. About eight samples of

Manuscript received.

I.V.L.P.K.D. Deepika, L. Preethi, K.V. Ramesh, Department of Chemical Engineering, Andhra University, Visakhapatnam-530003, India. *Corresponding author (e-mail: kvramesh69@yahoo.com).

K. Gouru Naidu, Department of Engineering Chemistry, GMRIT, Rajam-532127, India. branded waters have been obtained and were analyzed. These samples were numbered serially from 11 to 18 . An examination of the labels of these bottles revealed that the TDS information is not displayed. Further a vast majority of them also not shown the expiry date. A close examination of the entries in Table.1 reveals that the TDS levels in these samples varied from 9 to $48 \mathrm{ppm}$ indicating that all these waters are not healthy. Atleast a minimum $150 \mathrm{ppm}$ of TDS should be present in the waters for being potable. If one examines that sample no. 13 has a TDS level of only 9 ppm showing that it is as good as distilled water. Drinking these waters for longer periods definitely leads to ill health causing reduced levels of sodium, and other essential compounds and micronutrients.

Many people purchase water bottles of 1 liter volume to satisfy their thirst. Several national and local brands were examined for TDS levels. Four such bottles were chosen in the present study and these are labeled as sample numbers 21 to 24. A close inspection of the TDS levels in these samples reveals that the TDS content is as minimum as $4 \mathrm{ppm}$ in a famous national brand and in other brands it varied upto a maximum of 52. This means that these waters are also not at all recommended for drinking purposes. Further, sample no. 22 , which had only $4 \mathrm{ppm}$ is almost equal to distilled water, which could exhibit great effect on human health if consumed for longer period.

Table.1. Sachet waters

\begin{tabular}{|c|c|}
\hline Sample No. & TDS (ppm) \\
\hline 11 & 32 \\
\hline 12 & 26 \\
\hline 13 & 09 \\
\hline 14 & 26 \\
\hline 15 & 32 \\
\hline 16 & 29 \\
\hline 17 & 48 \\
\hline 18 & 16 \\
\hline
\end{tabular}

Table.2. Bottled waters (1 liter)

\begin{tabular}{|c|c|}
\hline Sample No. & TDS (ppm) \\
\hline 21 & 27 \\
\hline 22 & 04 \\
\hline 23 & 52 \\
\hline 24 & 31 \\
\hline
\end{tabular}

Several households now-a-days are resorting to bottled waters to meet their regular drinking water requirements. Therefore they are buying bulk water bottles i.e., 20 liter water bottles. Three brands which are very famous in Visakhapatnam are examined for TDS levels in the present study and the results are compiled in Table.3. These samples were numbered as 31,32 and 33. A look at the TDS levels in these samples made us know that the TDS was about $50 \mathrm{ppm}$. One can now say that these waters are also not suitable for potable purposes because of their low TDS levels. 
Table.3. Bottled waters (20 liter)

\begin{tabular}{|c|c|}
\hline Sample No. & TDS (ppm) \\
\hline 31 & 42 \\
\hline 32 & 51 \\
\hline 33 & 55 \\
\hline
\end{tabular}

Investigations were also carried out to examine the TDS levels in RO plants established by NGOs. Samples from two such plants were collected in the present study. These samples were labeled as 41 and 42 . Both input and output waters were collected and tested. A close examination of these results reveals that these waters meeting the standards as far as TDS level is concerned.

Table.4. Public RO units

\begin{tabular}{|c|c|c|}
\hline \multirow{2}{*}{$\begin{array}{c}\text { Sample } \\
\text { No. }\end{array}$} & \multicolumn{2}{|c|}{ TDS (ppm) } \\
\cline { 2 - 3 } & Input & Output \\
\hline 41 & 266 & 145 \\
\hline 42 & 484 & 244 \\
\hline
\end{tabular}

Table.5. Domestic water purifiers

\begin{tabular}{|c|c|c|}
\hline \multirow{2}{*}{$\begin{array}{c}\text { Sample } \\
\text { No. }\end{array}$} & \multicolumn{2}{|c|}{ TDS (ppm) } \\
\cline { 2 - 3 } & Input & Output \\
\hline 51 & 396 & 31 \\
\hline 52 & 136 & 136 \\
\hline 53 & 96 & 96 \\
\hline
\end{tabular}

Further, it is thought of examining the waters obtained from domestic purifiers. Therefore, samples were collected from three such branded purifiers and these samples are labeled as 51, 52 and 53. The test results were compiled in Table.5.
Both input and output waters were examined. A close inspection of the contents of Table. 5 reveals that the input TDS content for sample no. 51 is 396 and the output is 31 . This means that the input waters contain the TDS levels in the prescribed range whereas the output waters are not potable. This means that this purifier contained RO unit. Generally, the public should be aware of when to use RO purifier and when not to. Examination of other two samples reveals that there is no change in TDS content and both these waters are potable.

\section{CONCLUSION}

Waters available for drinking purpose from several commercial sources in Visakhapatnam have been examined for their potability with reference to the TDS levels. Among 15 bottled or sacheted water samples, none of them met the prescribed standards with reference to TDS. Further, the waters obtained from public RO units and from purifiers without RO units are meeting the required standards.

\section{REFERENCES}

1. WHO, Guidelines for drinking water quality: recommendations, Vol. I 3/e, Geneva (2004).

2. E. Pip, Survey of bottled drinking water available in Manitoba, Canada, Environmental Health Perspectives, 108(9) 863-866 (2000).

3. L.S. Clesceri, A.E. Greenberg, A.D. Eaton, Standard methods for the examination of water and waste water, $20^{\mathrm{ed}}$, APHA, USA. 